\title{
Contribution to growth and increment analysis on the Italian CONECOFOR Level II Network
}

\author{
Gianfranco FABBIO* and Emilio AMORINI \\ Istituto Sperimentale per la Selvicoltura, Viale S. Margherita 80, I 52100 Arezzo, Italy \\ *e-mail corresponding author: issar@ats.it
}

\begin{abstract}
The paper deals with the "Estimation of growth and yield" included in the National Programme on Intensive Monitoring of Forest Ecosystems CONECOFOR Aims of the paper are: i) to outline the composition and design of Level II PMPs network, also examining the structural characteristics of forest stands; ii) to describe the contents of mensurational surveys carried out in winter 1996/97 and 1999/00; iii) to analyse the growth rates in progress at each PMP using selected descriptors. Stand origin (11 high forests and 13 stored coppices and transitory crops) and the number of forest types tested are focused as the main discriminants of the PMPs network. This composition, together with irregular forestry practice, results in a number of consequences (prevailing age classes, tree densities and related stand structures, growth patterns) which cause a high in-and-between variability of all growth parameters. For the purposes of this analysis, the network of the plots was divided into three main sets: broadleaved high forest (i.e. beech stands), 6 PMPs; coniferous forest (i.e. Norway spruce stands), 5 PMPs; coppice forest (i.e. deciduous and evergreen oaks, beech and hardbeam stands), 13 PMPs. The measurement of basic growth variables (dbh and tree height) was used to describe the tree populations in each PMP; the calculation of basal area, mean and top dbh, mean and top height, provided the reference dataset at each inventory. The assessment of social class according to Kraft gave information on vertical stand structure and made it possible to analyse growth according to tree layers. Data comparison provided increments in the interval 1997-2000. The occurrence of natural mortality and ingrowth was also assessed to take into account their combined effect on tree population dynamics. No trend was found, due to limited data availability, but it was possible to have a detailed overview of the stand situation and growth rates in PMPs.
\end{abstract}

Key words: forest monitoring, permanent plots, tree growth, increment assessment

\section{INTRODUCTION}

The second dataset concerning growth and yield in level II plots became available in winter 1999/2000, three vegetation periods after the first survey, which was carried out in winter 1996/97.

The fact that the survey was repeated earlier than the planned 5 year interval (ICP Manual 1998) is due to the delayed start of the project (1996) and to the demands of synchronisation at trans-national level (2000). This means that the number of surveys is too few and the observed growth period too short to reveal trends, but are sufficient to provide an overview on the stand situation and growth rates in each plot.

\section{MATERIAL AND METHODS}

The level II network was installed with 20 permanent monitoring plots (PMPs), each of $2500 \mathrm{~m}^{2}$, representing the commonest tree species and forest types throughout the Italian peninsula (Allavena et al. 1999). The number of PMPs increased to 24 in the $2^{\text {nd }}$ survey, four plots being added (TOS2, TOS3, LOM2, LOM3) in 1999.

Stand origin is the main discriminant: 11 are high forests and 13 stands are already managed under the coppice system (stored and transitory crops), closely reflecting forest management practice in Italy. Stored coppice and transitory crop are specific terms referring to the progressive suspension of harvesting on a part of the coppice area. Stored coppice is an aged stand, not clearcut at the traditional rotation, and called "stored" because of natural biomass storage with ageing. Transitory crop is an aged coppice undergoing periodical thinnings which drastically reduce shoot density and shape the stand structure into the physiognomy of a high forest aged in the same way. This kind of network composition produces a number of consequences, such as different prevailing age classes, tree densities, related stand structures and growth patterns. The number of forest types tested further increased the previously existing variability in all descriptive parameters (Fabbio 1997). The Level II network design provides a realistic picture of forest diversity in a Mediterranean country and makes it possible to survey a number of tree species and forest types, but, in contrast, does not allow monitoring activities to be concentrated on a few target ecosystems.

Each plot was inserted into a wide homogeneous area (minimum of 10 hectares) representative of local growing conditions. Each PMP is a case-study because of the network design (preferential sampling, no explicit model adopted) (Ferretti et al. 2000), which greatly limits any inferential process (Stevens 1994; Edwards 1998 in Ferretti 2000).

Subjects of analysis were the forest stand, i.e. the spatially continuous set of trees growing under similar

Paper prepared within the CONECOFOR programme, by the contract with the Ministry for Agriculture and Forestry Policy - National Forest Service, Italy. CONECOFOR is part of the Pan-European Level II Intensive Monitoring of Forest Ecosystem and is co-sponsored by the European Commission. 
environmental conditions (soil and climate) and site factors (altitude, aspect, slope gradient, geomorphology, etc.); the stand structure, i.e. the local distribution of trees over the growing space; the individual trees (Prodan 1968; Hara 1986; Oliver \& Larson 1990).

As far as growth analysis is concerned, a further source of in-and-between PMP variability is the wide range of tree density within the same forest type and age class, due to the irregular forestry practice typical of most Italian high forests, and to the suspension of harvesting on a share of the coppice area.

At each inventory the basic growth variables were measured: dbh of all living trees above the threshold of 3 or $5 \mathrm{~cm}$ in coppices and in high forests respectively; tree height by random sampling over the dbh range. Basal area, mean and top dbh, as well as volume of standing crop were calculated. Mean and top height were estimated by plot specific tree height vs dbh functions. Stand age was estimated and past radial stem growth assessed by core sampling in the upper tree storey (dominant and co-dominant trees) at the first inventory (Amorini \& Fabbio 1997). A survey of tree height, height to crown base and crown width on the same trees as were selected for coring in the buffer area provided data which were used to establish allometric relationships of crown width and crown length $v s$ dbh (Amorini et al. 1999).

Plot size was checked at the time of the $1^{\text {st }}$ survey. Deviations from the expected size were taken into account at calculation of data per unit area (hectare).

The assessment of social class according to Kraft provided information on vertical stand structure and pointed out the role played by each tree species in mixed stands, as well as the contribution of each storey (stem frequency and basal area distributions vs dbh per species and storey). Total growth rate for the whole stand was then stratified into tree sub-populations and growth rates per storey determined (Amorini \& Fabbio 1997, 2000).

Repetition of the measurements made it possible to check the $1^{\text {st }}$ field survey carried out in 1997 , so that inconsistent values could be corrected. As to dbh and tree height, correction involved 1997 values which were equal or higher than the values for 2000. In such cases, individual measurements were repeated in the $2^{\text {nd }}$ survey to verify error legitimacy. Corrected dbh values were then estimated according to the following calculation:

Corrected dbh1997 = recorded dbh 2000

- dbh increment1997-2000 in the social class

For this purpose, periodical increments per social class and per plot were determined on the set of trees showing consistent dbh assessments at both surveys, erroneous observations excluded (Fabbio et al. 2000).

In a few cases the $2^{\text {nd }}$ survey detected, besides the ingrowth of small-sized trees, the presence of trees above the threshold evidently ignored at the first inventory. Former dbhs were calculated according to (1 and these trees were added to the 1997 dataset. The revised basal area per plot and per hectare in 1997 was calculated from the dbh check. These values are close to those already reported in Fabbio \& Amorini (2000), the differences being a few square meter decimals per hectare. In one plot only (TOS1) the difference is larger (30.14 against $26.21 \mathrm{~m}^{2} \mathrm{ha}^{-1}$ ); this was due to difficulty in identifying the plot boundaries, which caused the exclusion of a few coppice stools in the first survey.

Inconsistent tree height values were corrected as follows: Tree h.1997 corr. $=$ h.1997adj.* h.2000 obs.
/ h.2000 adj.

where: adjusted values were derived from the 2000 height curve.

Following this check, tree height $v s$ dbh functions in 1997 were re-calculated for each plot. Note that instruments of differing accuracy were used in each inventory to estimate this variable: Blume Leiss in the first, Vertex in the second, which should be taken into account.

Dominated or suppressed tree classes in overstocked plots (mainly stored coppices) often showed incremental rates close to zero, these components of the population being next to the tree mortality area naturally in progress in these PMPs at the ages observed.

Size and cumulative frequencies of errors detected in the 1997 survey were elaborated at network level (Fabbio et al. op.cit.).

\section{RESULTS AND DISCUSSION}

\subsection{Factors affecting growth rates}

Under the general statement that dynamics within forest ecosystems takes place over different temporal and spatial scales (Innes 1998), growth allocation is basically an individual (tree) attribute. A tree population is a hierarchical set of interacting organisms showing growth rates which vary individually within the same growing season and from year to year. The total number of trees is also variable as a result of ingrowth (trees exceeding the calliper limit) and mortality. Ingrowth and mortality therefore act as forces driving the numerical dynamics of tree populations at observed intervals, their progress varying according to stand origin, initial tree density, stand age, spatial aggregation pattern and vertical structure of stands. Their occurrence, incidence and location over the dbh range overlap current population growth, the two terms constituting an input/output at each growth assessment period (Fabbio \& Amorini 1999).

In this context, growth calculation assesses individual tree size variation and tree population growth in the measurement area at planned times.

The elaboration of the surveyed variables records the state of growth in each PMP and establishes the reference datasets at each inventory. Among the calculated 
variables, basal area (i.e. the summation of circular areas at $1.3 \mathrm{~m}$ of all trees alive in the plot related to the unit area $\left[\mathrm{m}^{2} \mathrm{ha}^{-1}\right]$ ); mean height (i.e. the height of mean basal area tree $[\mathrm{m}])$; top height (i.e. the height of mean basal area tree among the 25 thickest stems in the plot [m]) were selected as descriptors for stand situation and growth tendency. Basic features and qualities of these classic forest measurement parameters are reported in Fabbio \& Amorini (2000). In this connection, it seems useful to recall that the response ability of descriptors also depends on the sensitivity or complacency of tree species to the positive inputs or stresses due to site or environmental factors. These attributes are also related to site quality, given its possible range from the optimum to the specific ecological boundaries in the sites tested. The location of PMPs in typical vegetation areas of tree species concerned reduces the potential sitequality range and its related uncertainty.

A further, major effect on response ability of growth indexes to explain stand dynamics derives from the already mentioned irregularity of forestry practices. Under a regular thinning regime, tree numbers decrease in time according to a definite pattern which, despite the fact that there may be marked differences among cultivation schemes, maintains a generally low level of intertree competition over the full management cycle. Conversely, if trees are not thinned at regular intervals, competition is enhanced, which affects individual growth and survival concealing natural trends and causing storied structures as early as the juvenile phase. As far as growth and increment assessment are concerned, a differentiated cultivation history within the same species and forest type constitutes a disturbance factor which increases the range of growth rates in the observed tree populations. Moreover, the fact that there is at present no management on most PMPs will influence the development of basal area and mean height for the expected duration of the project.

The resulting parameters consistently describe actual growth dynamics within each PMP, but the total value should take into account the inner structure of growth function of past and current tree density - which varies between PMPs. In short, growth index consistency is not variable in itself, but is dependent on the physical arrangement of standing crops. An additional, suited analytical procedure may to some extent overcome the problem. A proposal relating to the Italian network is made in the text.

\subsection{Data arrangement}

Table 1 shows the main parameters in 1999/00 and periodical increments calculated on the revised values following the 1997 survey check. Tree mortality and ingrowth data are also given to further explain the dynamics in each PMP. As far as basal area is concerned, the periodical increment for 1997-2000 is expressed: i) by a comprehensive value referring to the actual tree population surveyed at each inventory $\left(\mathrm{G}_{0}\right)$ and ii) by a second value including only trees which were alive and measured (paired observations) at both inventories $\left(G_{1}\right)$. In this way the influence of current mortality and ingrowth on the periodical increment was eliminated.

For analytical purposes, the network of plots has been divided into three main sets:

- $\quad$ high broadleaved forest, i.e. beech stands, including 6 PMPs (ABR1, CAL1, CAM1, PUG1, VEN1, TOS3) and covering the latitudinal range of beech vegetation in Italy from the Southern Apennines to the Alps;

- coniferous forest, i.e. Norway spruce stands, including 5 PMPs (FRI2, LOM1, LOM2, TRE1, VAL1) located on the southern slopes of the Alps;

- coppice forest, including 13 PMPs, both stored coppices and transitory crops, made up of deciduous oaks (BAS1, EMI1, LAZ1, MAR1, SIC1, UMB1), evergreen oak (SAR1, TOS1, TOS2), beech (EMI2, LOM3, PIE1) and hardbeam (FRI1). These PMPs are located on the Italian islands (Sardinia and Sicily), the Apennines and the foothills of the Alps.

The first two sets of forest types are common in Europe, whilst the third set is more typical in Mediterranean countries. The three groups will be analysed and discussed separately, given their different characteristics as regards stand structures, age classes and growth parameters.

Number of trees, basal area and top height values $v s$ age of the three groups are reported in figures 1 to 3 .

\subsection{The beech stands}

This group is characterised by similar stand ages (85 to $110 \mathrm{y}$ ) in 5 out of 6 PMPs (only TOS3, added in $1999 / 00$, being aged 150 ), and site indexes $\left(1^{\text {st }}\right.$ to $2^{\text {nd }}$ class according to available yield tables [Castellani 1982]). All the forests concerned are natural mountain stands located on public land and have an irregular silvicultural background (VEN1 excepted), or have shifted from wood-production oriented to conservative management.

Harvesting and thinning have no longer been practised for some decades. The forest of Cansiglio (VEN1) is the only location where periodical thinning and regeneration cutting (shelterwood system) are currently performed. Tree density per unit area is of course highly variable (228 to 993 live stems per hectare above the threshold of $5 \mathrm{~cm}$ ) in spite of similar stand ages, as a function of different vertical structures and of the occurrence of canopy gaps which allowed the establishment of advance regeneration patches. Clusters of younger, small-sized trees, suppressed to the main tree layer, thus contribute to the high tree number in ABR1 and PUG1. Both mortality and ingrowth are concentrated on the left side of the tree frequency distribution. 
Tab. 1. Growth parameters (inventory 2000) and periodical increments (1997-2000) surveyed at each PMP. ${ }^{(1)}$ average age in the dominant storey in those PMPs where, due either to the irregular silvicultural practice or to the applied management system (group selection system), more than one age class is present in the main crop; ${ }^{(2)}$ living trees. Minimum dbh surveyed $=3 \mathrm{~cm}$ in coppice forests; $=5 \mathrm{~cm}$ in high forests and transitory crops; ${ }^{(3)} \mathrm{G}_{2000}-\mathrm{G}_{1997}{ }^{(4)}$ ( $\mathrm{G}_{2000}$ - ingrowth) - $\left(\mathrm{G}_{1997}\right.$ - mortality); ${ }^{(5)} \mathrm{dbh}$ of average basal area tree; ${ }^{(6)}$ average $\mathrm{dbh}$ of 100 largest trees per hectare; ${ }^{(7)}$ adjusted tree heights corresponding to mean and dominant dbhs; ${ }^{(8)}$ stored coppices undergoing conversion into high forest. One or more thinnings carried out in the original stored crops.

\begin{tabular}{|c|c|c|c|c|c|c|c|c|c|c|c|c|c|c|c|c|c|c|c|}
\hline $\begin{array}{l}\tilde{O} \\
\dot{U} \\
\frac{0}{2}\end{array}$ & 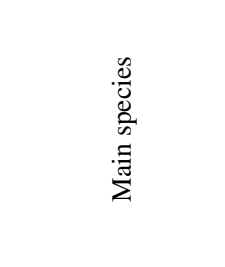 & 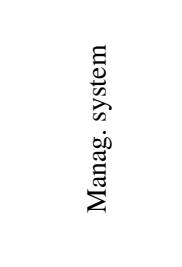 & 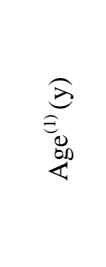 & 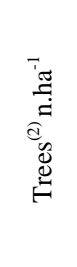 & 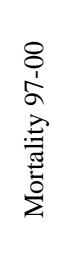 & $\begin{array}{l}8 \\
1 \\
1 \\
\sigma \\
5 \\
5 \\
0 \\
0 \\
0 \\
\Xi \\
\Xi\end{array}$ & 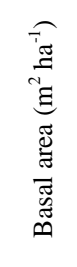 & $\begin{array}{l}8 \\
\text { 1 } \\
\text { on } \\
\text { م, } \\
0 \\
y\end{array}$ & 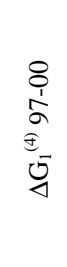 & 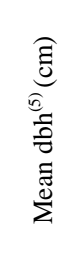 & 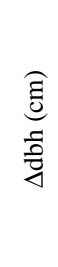 & 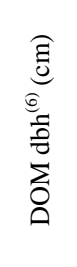 & 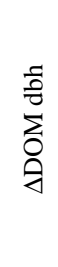 & 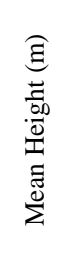 & 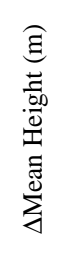 & 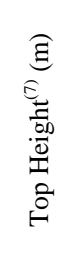 & 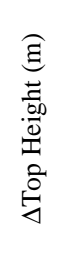 & 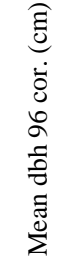 & 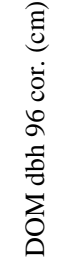 \\
\hline [01] ABR1 & Igus syl & $\mathrm{h}$ & 110 & 879 & 33 & 13 & .31 & 2.22 & 39 & 24.8 & 1.1 & 2.1 & 1.1 & 20.2 & 0.7 & 25.3 & 0.7 & 23.7 & 41 \\
\hline [02] BAS 1 & Quercus cerris & trans. $\operatorname{crop}^{(8)}$ & 65 & 868 & 49 & - & 42.03 & 1.18 & 1.37 & 24.8 & 1.0 & 44.7 & 2.2 & 17.7 & 0.8 & 21.3 & 1.1 & 23.8 & 42.5 \\
\hline [03] CAL1 & Fagus sylvatica & high forest & 110 & 321 & 12 & - & 40.65 & 0.75 & 0.97 & 40.2 & 1.1 & 57.9 & 1.0 & 25.8 & 1.7 & 30.9 & 2.3 & 39.1 & 56.9 \\
\hline [04] CAM1 & Fagus sylvatica & high forest & 100 & 228 & - & - & 49.98 & 2.41 & 2.41 & 52.4 & 0.9 & 62.8 & 1.5 & 28.3 & 1.5 & 29.6 & 1.6 & 51.5 & 61.3 \\
\hline [05] EMI1 & Q.petraea Q.cerris & s stored coppice & 45 & 2205 & 189 & 337 & 26.06 & 0.38 & 2.39 & 12.3 & -0.3 & 31.0 & 1.5 & 12.8 & -0.1 & 19.6 & 0.5 & 12.6 & 29.5 \\
\hline [06] EMI2 & Fagus sylvatica & stored coppice & 40 & 4172 & 552 & 184 & 36.52 & 0.75 & 3.08 & 10.6 & 0.6 & 23.3 & 1.0 & 13.2 & 0.8 & 14.4 & 0.8 & 10 & 22.3 \\
\hline [07] FRI1 & Carp.bet. Q.robur & stored coppice & 45 & 1098 & 169 & 41 & 26.65 & 2.60 & 2.83 & 17.6 & 1.1 & 31.6 & 1.9 & 17.7 & 1.8 & 24.9 & 2.6 & 16.5 & 29.7 \\
\hline [08] FRI2 & Picea abies & high forest & 110 & 576 & - & 44 & 55.78 & 2.88 & 2.85 & 35.1 & -0.1 & 47.7 & 1.6 & 29.6 & 0.5 & 33.7 & 1.1 & 35.2 & 46.1 \\
\hline [09] LAZ1 & Quercus cerris & stored coppice & 35 & 1617 & 12 & - & 26.56 & 2.62 & 2.72 & 14.5 & 0.8 & 24.8 & 1.5 & 14.8 & 1.5 & 17.9 & 1.1 & 13.7 & 23.3 \\
\hline [10] LOM1 & Picea abies & high forest & 80 & 1019 & 24 & - & 43.73 & 3.50 & 3.74 & 23.4 & 1.2 & 51.6 & 2.2 & 19.3 & 1.0 & 27.2 & 1.1 & 22.2 & 49.4 \\
\hline [11] MAR1 & Quercus cerris & stored coppice & 35 & 4364 & 275 & 406 & 38.88 & 3.04 & 3.85 & 10.7 & 0.3 & 22.0 & 1.4 & 12.6 & 0.5 & 18.7 & 0.8 & 10.4 & 20.6 \\
\hline [12] PIE1 & Fagus sylvatica & trans. c & 55 & 1187 & 26 & - & 71 & 1.78 & 1.96 & 18.1 & 0.7 & 34.7 & 1.5 & 15.6 & 0.4 & 20.0 & 0.0 & 17.4 & 33.2 \\
\hline [13] PUG1 & Fagus sylvatica & high forest & 85 & 993 & 99 & 152 & 46.57 & 2.80 & 3.73 & 24.4 & 0.9 & 47.6 & 2.1 & 24.3 & 1.7 & 28.5 & 1.0 & 23.5 & 45.5 \\
\hline [14] SAR1 & Quercus ilex & stored coppice & 50 & 1540 & 186 & 16 & 41.51 & 0.97 & 1.94 & 18.5 & 1.2 & 29.1 & 0.8 & 14.7 & 1.2 & 17.7 & 1.0 & 17.3 & 28.3 \\
\hline [15] SIC1 & Quercus cerris & trans. crop & 50 & 839 & 16 & - & 26.21 & 1.20 & 1.46 & 19.9 & 0.6 & 26.9 & 0.8 & 15.8 & 1.2 & 18.4 & 1.5 & 19.3 & 26.1 \\
\hline [16] TOS1 & Quercus ilex & stored coppice & 50 & 2327 & 240 & 163 & 30.19 & 0.05 & 1.59 & 12.9 & 0.4 & 37.7 & 2.0 & 12.8 & 1.2 & 17.4 & 2.0 & 12.5 & 35.7 \\
\hline [17] TRE1 & Picea abies & high forest & $120-200$ & 389 & 4 & - & 55.54 & 1.65 & 1.66 & 42.6 & 0.8 & 56.3 & 1.0 & 28.9 & 0.7 & 32.3 & 1.8 & 41.8 & 55.3 \\
\hline [18] UMB1 & Quercus cerris & trans. crop & 75 & 731 & 12 & 4 & 35.75 & 1.83 & 2.03 & 25.0 & 0.8 & 36.5 & 0.9 & 25.9 & 1.5 & 30.1 & 1.6 & 24.2 & 35.6 \\
\hline [19] VAL1 & Picea abies & high forest & 150 & 736 & 9 & - & 52.41 & 2.23 & 2.57 & 30.1 & 0.8 & 46.5 & 1.4 & 20.3 & 0.3 & 25.0 & 0.3 & 29.3 & 45.1 \\
\hline [20] VEN1 & Fagus sylvatica & high forest & 110 & 345 & - & - & 36.27 & 1.63 & 1.63 & 36.6 & 0.8 & 47.8 & 1.4 & 25.1 & 1.2 & 26.8 & 1.6 & 35.8 & 46.4 \\
\hline [23] LOM2 & Picea abies & high forest & 70 & 985 & - & - & 58.86 & - & - & 27.6 & - & 46.2 & - & 24.1 & - & 30.6 & - & - & - \\
\hline [24] LOM3 & Fagus sylvatica & trans. crop & 50 & 816 & - & - & 24.96 & - & - & 19.7 & - & 32.3 & - & 19.1 & - & 21.5 & - & - & - \\
\hline [25] TOS2 & Quercus ilex & stored coppice & 60 & 3560 & - & - & 36.16 & - & - & 11.4 & - & 32.4 & - & 13.9 & - & 17.0 & - & - & - \\
\hline [26] TOS3 & Fagus sylvatica & high forest & 150 & 464 & - & - & 62.40 & - & - & 41.4 & - & 57.2 & - & 31.5 & - & 36.2 & - & - & 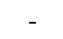 \\
\hline
\end{tabular}

The data in table 1 show a general trend related to tree density per unit area, given the low variation of site-index and age range among PMPs. Basal area varies between 36.3 and $50.0 \mathrm{~m}^{2} \mathrm{ha}^{-1}$, the oldest plot (TOS3) reaching $62.4 \mathrm{~m}^{2} \mathrm{ha}^{-1}$; basal area increment 1997-2000 ranges from 0.8 to $2.8 \mathrm{~m}^{2} \mathrm{ha}^{-1}$ (1.0 to 3.7 without taking account of mortality and ingrowth). Mean and dominant dbh (24.4 to 52.4 and 42.1 to $62.8 \mathrm{~cm}$ ) increased by 0.8 to 1.1 and by 1.0 to $2.1 \mathrm{~cm}$ respectively. The influence of current mortality and ingrowth on the calculation of the dbh of mean basal area tree variation must be considered. Mean height reaches 20.2 to $28.3 \mathrm{~m}$ (31.5 at TOS3) and top height 25.3 to $30.9 \mathrm{~m}$ (36.2 at TOS3). The mean-top height difference inside each PMP is variable and closely related to the vertical arrangement of stand structure i.e. tree density in the main tree layer. Tree height increment varies from 0.7 to $1.7 \mathrm{~m}$ (mean height) and from 0.7 to $2.3 \mathrm{~m}$ (top height). The above observation about the dbh of mean basal area tree of course affects mean height assessment where mortality or ingrowth counteract the natural right-sided shift of dbh distribution.

\subsubsection{Growth composition \& structure in beech PMPs}

A further step towards improving growth indicators' consistency has been taken in these PMPs. The approach, already reported in Fabbio \& Amorini (2000), particularly involves the observed forest structures showing high in-and-between variability and is aimed at testing the indicators' ability to explain the different growth rates within each tree population. The procedure is also consistent with the statements of "Growth Panel" (Dobbertin et al. 2000), which recall the information about stand structure or single tree properties as explanatory variables for other measurements carried out on Level II plots and as response variables of environmental and stress factors.

The analysis, aimed at assessing inner growth composition and structure, involved the stratification of trees into clearly distinguishable layers (upper, intermediate, dominated, suppressed), to reduce the subjectivity which individual social attribution is prone to. Basal area increments (b.a.i.) and relative averages per layer were then determined and compared with the total 
growth rates within each PMP. Through this comparison it was possible to quantify the contribution of each layer, highlight the different growth rates and qualify the total stand growth. Average b.a.i. in the upper layer was then compared with average value per plot among the PMPs. This highlighted how similar growth rates in the leading components of the tree population match with different rates per plot, these incorporating the variability across stand structures.
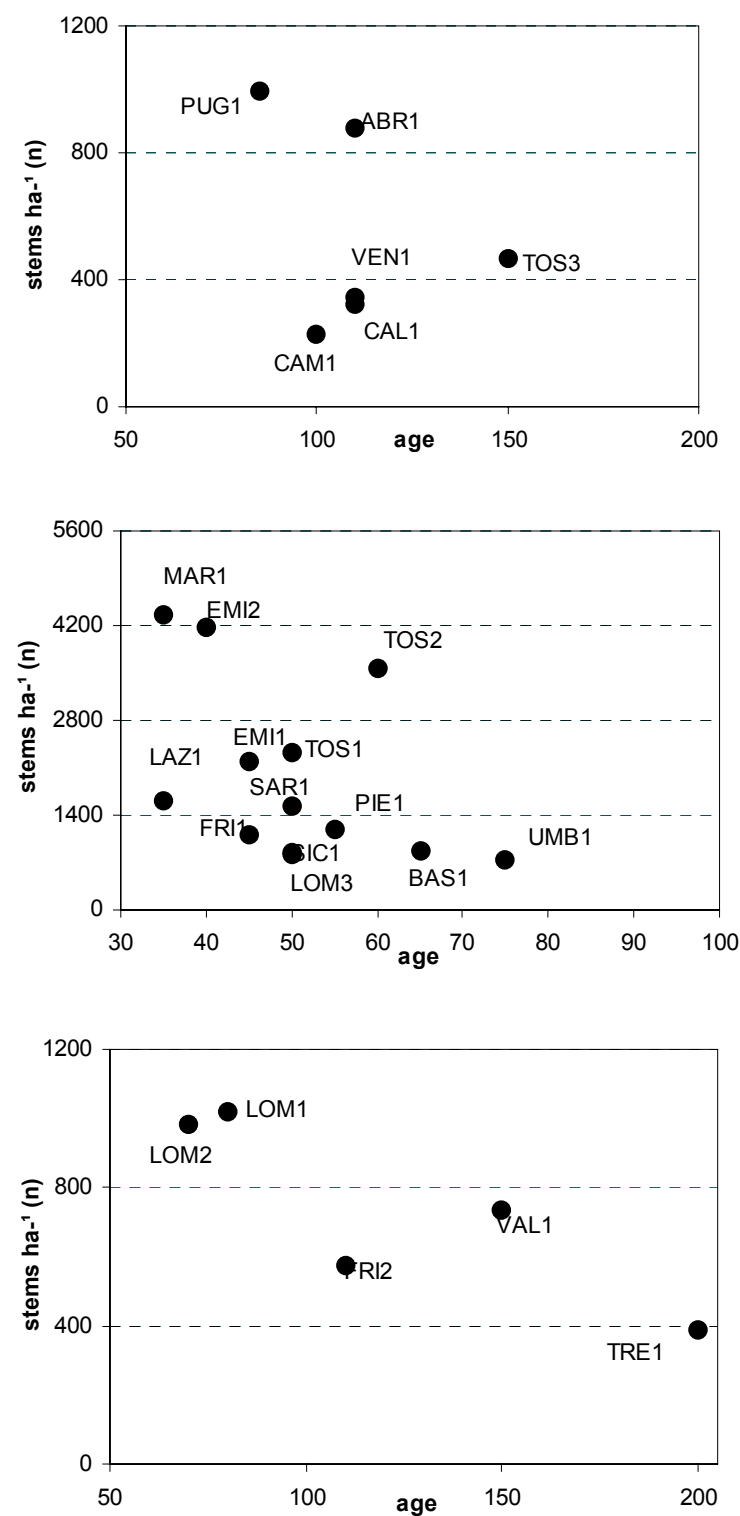

Fig.1. Tree number $v s$ stand age at beech high forests (upper), coppice stands (middle) and Norway spruce forests (lower).

The distribution of trees per b.a.i. class and per layer, showing the distributive growth pattern in each PMP, was then analysed. This is the basis for our proposal to find, at each inventory and in each plot, a subset of growth-indicator trees selected from dominant trees which show the prevailing allocation rates (modal and close to modal classes). This suggestion rests on the assumptions that: i) growth response is more easily detected on dominant trees, as they are less influenced by inter-individual competition; ii) they are reliable growth tendency descriptors because of their favourable growth environment as well as their own ability to use site capacity (Ker 1953; Kira et al. 1953; Kozlowski \& Peterson 1962; Harper 1967; Hamilton 1969; Assmann 1970; Roberts et al. 1993; Oliver \& Larson op. cit.). Size-consistency between average dbh of dominant trees establishing modal and close to modal b.a.i. classes in each PMP and average dominant dbh per plot, was finally verified under regular age-related densities.
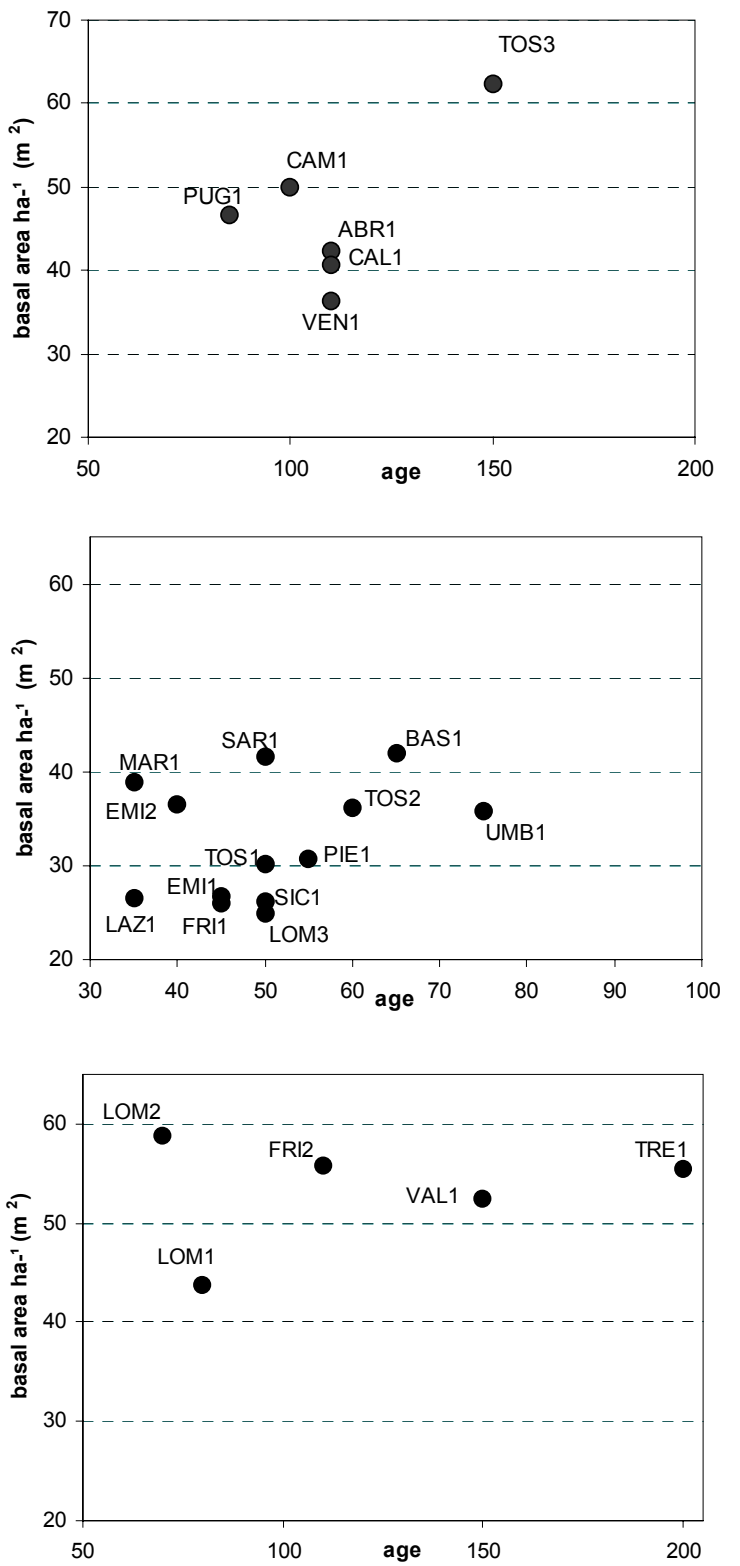

Fig. 2. Basal area $v s$ stand age at beech high forests (upper), coppice stands (middle) and Norway spruce forests (lower). 

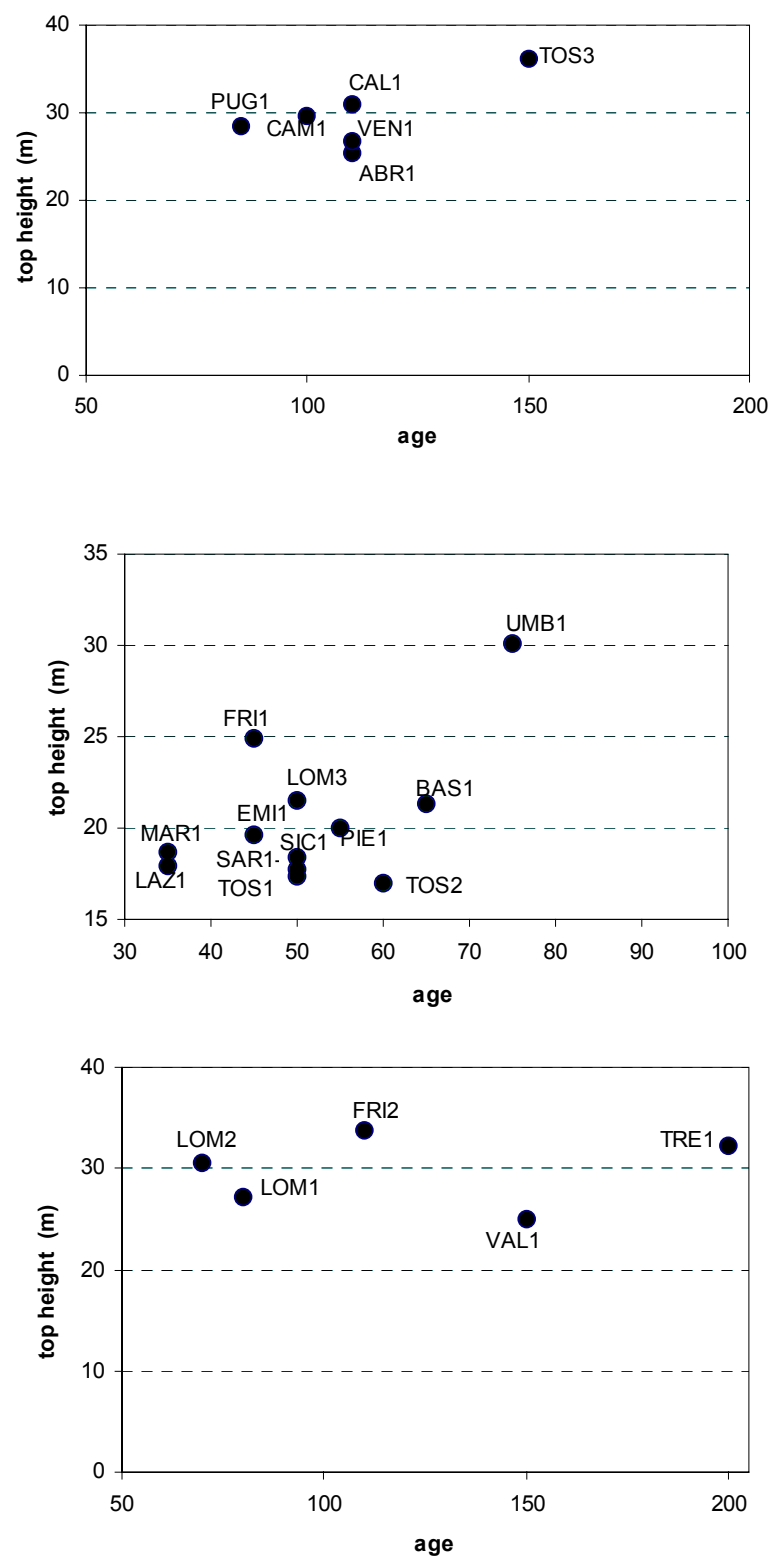

Fig. 3. Top height $v s$ stand age at beech high forests (upper), coppice stands (middle) and Norway spruce forests (lower).

\subsection{Norway spruce stands}

Coniferous forest is represented by 5 PMPs located from west to east (VAL1, LOM1, LOM2, TRE1, FRI2) over the alpine range. Most of these forests were in the past, and are still today, managed for timber production according to codified silvicultural practices providing for both even and uneven aged stand structure (clearcutting, shelterwood and group selection system).

Two PMPs (VAL1 and LOM1), aged 150 and 80, show a typically stratified arrangement and the presence of small gaps where regeneration patches of spruce or of the accompanying species, either conifers or broadleaves, have become established. Three PMPs (LOM2, TRE1, FRI2) are single-storied and aged 70
(LOM2) and 110 (FRI2), whilst the main tree layer is uneven aged in TRE1 (120-200 y). Canopy cover is similar (70-80\%) in all the PMPs independently of tree density, varying over the whole set from 389 to 1019 stems per hectare.

Basal area ranges from 43.7 (LOM1) to $58.9 \mathrm{~m}^{2} \mathrm{ha}^{-1}$ (LOM2); the basal area increment in 1997-2000 varies from 1.6 to $3.5 \mathrm{~m}^{2} \mathrm{ha}^{-1}$ (1.7 to 3.7 not taking mortality and ingrowth into account). Mean and dominant dbh (23.4 to 42.6 and 46.5 to $56.3 \mathrm{~cm}$ ) show increments varying from 0.8 to 1.2 and 1.0 to $2.2 \mathrm{~cm}$ respectively, while mean basal area tree increment is negative in FRI2 due to the ingrowth of small-sized trees. Mean and top height vary from 19.3 to 29.6 and 25.0 to $33.7 \mathrm{~m}$ respectively, these values also depending on site-index, age range and different vertical arrangement of standing crops. Mean and top height increments show the following ranges: $0.3-1.0$ and $0.3-1.8 \mathrm{~m}$.

\subsection{Coppice stands}

Stands already managed under the coppice system are represented by 11 PMPs, 13 including TOS2 and LOM3, which were added at the 1999-00 inventory. These PMPs give a realistic picture of diversity in the coppice forests, due to the evolution which followed the suspension of harvesting under traditional rotations. There is therefore a wealth of information concentrated in the observed PMPs, bringing together the main structural and compositional types throughout the Italian peninsula.

The whole set may be sorted into four groups as follows: Turkey oak (deciduous) (6 PMPs), holm oak (evergreen) (3 PMPs), beech (3 PMPs) and mixed hardbeam-deciduous oak stands (1 PMP). The PMPs are located from the Southern islands through the Apennines and up to the foothills of the Alps. Sites are hilly to mountainous, with the exception of FRI1 (plain), and are representative of massive vegetation areas of the tree species concerned.

As already mentioned, two types of coppice forests are present: stored coppices and transitory crops, with different tree densities at similar ages as their most distinctive feature. The pattern of tree density in stored coppices may be quite different as a function of the auto ecology of the main component species (light demanding or shade tolerant sp.) and of accompanying shade tolerant species setting up a dense layer, subsidiary to the main tree cover.

The full age range varies from 35 to $75 \mathrm{y}$, with most of the PMPs aged 40 to $55 \mathrm{y}$. Tree density is highly variable (731 to 4364 trees ha $^{-1}$ ), the numerical dynamics of tree populations in the observed interval being driven by mortality and ingrowth. The occurrence of these is especially evident in a few PMPs (see Tab.1), with mortality prevailing over ingrowth or vice versa in accordance with species auto ecology and the structural characteristics of the tree canopy. 
Tab. 2. Periodical basal area increment $(\Delta \mathrm{G})$ and average values per layer $(\Delta \mathrm{g})$ and per plot (total) at Turkey oak PMPs. In brackets the number of trees. B.a.i. in $\mathrm{cm}^{2}$.

\begin{tabular}{|c|c|c|c|c|c|c|c|c|c|c|c|c|}
\hline \multirow[t]{2}{*}{ Tree Layer } & \multicolumn{2}{|l|}{ BAS 1} & \multicolumn{2}{|l|}{ EMI 1} & \multicolumn{2}{|l|}{ SIC 1} & \multicolumn{2}{|l|}{ MAR 1} & \multicolumn{2}{|l|}{ UMB 1} & \multicolumn{2}{|l|}{ LAZ 1} \\
\hline & $\Delta \mathrm{G} 97-00$ & $\Delta \mathrm{g}$ & $\Delta \mathrm{G} 97-00$ & $\Delta \mathrm{g}$ & $\Delta \mathrm{G} 97-00$ & $\Delta \mathrm{g}$ & $\Delta \mathrm{G} 97-00$ & $\Delta \mathrm{g}$ & $\Delta \mathrm{G} 97-00$ & $\Delta \mathrm{g}$ & $\Delta \mathrm{G} 97-00$ & $\Delta \mathrm{g}$ \\
\hline Upp & $1830(58)$ & 32 & 3993 (126) & 32 & $1730(10$ & 17 & 5594 (204) & 27 & 2653 (74) & 30 & 4266 ( & 25 \\
\hline Dominated & 368 (105) & 4 & 147 (15) & 10 & 188 (34) & 6 & 376 (83) & 5 & 603 (36) & 17 & 585 (109) & 5 \\
\hline Total (plot) & 2942 (204) & 14 & 4452 (172) & 26 & 2855 (210) & 14 & 6734 (367) & 18 & 4073 (154) & 26 & 6292 (392) & 16 \\
\hline
\end{tabular}

Basal area ranges from 26.06 to $42.03 \mathrm{~m}^{2} \mathrm{ha}^{-1}$ and shows a wide incremental variation $\left(0.05\right.$ to $3.04 \mathrm{~m}^{2}$ $\mathrm{ha}^{-1}$ ) including mortality and ingrowth, the same values becoming 1.37 to 3.85 when the above factors are not taken into consideration. Mean dbh $(10.6$ to $25.0 \mathrm{~cm})$ has its minimum at overstocked plots, reaching a maximum at transitory crops where thinning has drastically reduced the original tree density. Dbh increment varies from 0.3 to $1.2 \mathrm{~cm}$; the values are conditioned by the left-sided shift of dbh distribution due to ingrowth. In this connection, a low increment (0.3 at MAR1), or even a negative value ( -0.3 at EMI1), recorded at PMPs where ingrowth is especially frequent, are a good illustration of this relationship. Dominant dbh shows a wider variation among PMPs (22.0 to $44.0 \mathrm{~cm}$ ) due to standards, i.e. trees twice or more the age of the coppice shoots released at each harvesting. Periodical increment varies from 0.8 to $2.2 \mathrm{~cm}$. Mean and top height range from 12.6 to 25.9 and 14.4 to $30.1 \mathrm{~m}$, relative increments being 0.4-0.8 and 0.5-2.6 m. No increment of top height, and a negative mean height increment $(-0.1 \mathrm{~m})$, were recorded at PIE1 and EMI1, respectively.

\subsubsection{Growth composition \& structure in deciduous oak PMPs}

In addition to the analysis of the total tree population, the working hypothesis already implemented for beech high forests was performed for Turkey oak plots (6 PMPs); deciduous oaks being so common, these represent the target forest type in the coppice area. Following the same procedure, trees were stratified into well-characterised layers (upper, intermediate and dominated), i.e. as a function of social class and potential growth ability (Tab. 2). The leading species only was considered in PMPs (e.g. EMI1 and MAR1) where there was a marked presence of subsidiary species growing prevalently in the intermediate and suppressed layers.

Growth composition data, in terms of basal area increment (b.a.i. $=\Delta G$ ), number of trees concerned (n), average b.a.i. $(\Delta \mathrm{g})$, are reported in the table. Using these data, a series of comparisons can be made within and among PMPs: i) $\Delta \mathrm{G}$ per layer $v s \Delta \mathrm{G}$ per plot points out the relative contribution in accordance with the vertical arrangement of trees; ii) $\Delta$ gs per layer highlight the well-differentiated growth ability according to the available resources in each growth environment; iii) $\Delta$ gs per layer $v s \Delta$ g per plot show the loss of information inherent to the comprehensive value; iv) $\Delta \mathrm{gs}$ in the upper layer $v s \Delta \mathrm{g}$ per plot highlights different ratios (variable between 1.2 and 2.2), the latter value incorporating the existing variability across stand structures.

The differentiation of growth rates according to layers indicates that it would be useful to have an overview on the inner structure of growth in each plot. For this purpose, trees were sorted per b.a.i. class and per layer (Fig. 4). Distributive patterns reveal the incremental range per layer and highlight the prevailing allocation rates, i.e. the convergence of a number of trees into a common growth performance. Modal class in the upper layer indicates the usefulness of identifying growth-indicator trees, as dominant trees: i) contribute a major share of current b.a.i.; ii) are less sensitive to internal stresses, such as inter-individual competition; iii) are more responsive to changes in the growth environment because of their ability to use the whole capacity of the site.

Descriptive statistics of $\Delta \mathrm{g}$ distribution can provide further information on growth trends at each inventory.

Other contributions to dynamics in deciduous oak PMPs are reported by Cutini (2000, 2002), who deals with annual litter production and LAI estimates, and by Manetti (2002), who analyses tree ring series by a dendroecological approach.

\section{CONCLUSIONS}

The second inventory detected values which were biased in the $1^{\text {st }}$ inventory, and provided preliminary information on growth in the Level II network. Although the observed growth period is too short to reveal any emerging trend, the data to update standing crop parameters and determine the growth rates within each PMP.

The network design, which included many forest types with different management regimes (coppice and high forest), and the irregular forestry practice which characterises most PMPs, produced a marked structural diversity which is well documented by the results. Basic stand-describing variables and derived parameters also show the wide range of growing conditions within the same forest types. The analysis tried to manage the high in-and-between variability affecting both response and explanatory ability of growth indicators. In this connection, ingrowth and mortality were considered and basal 

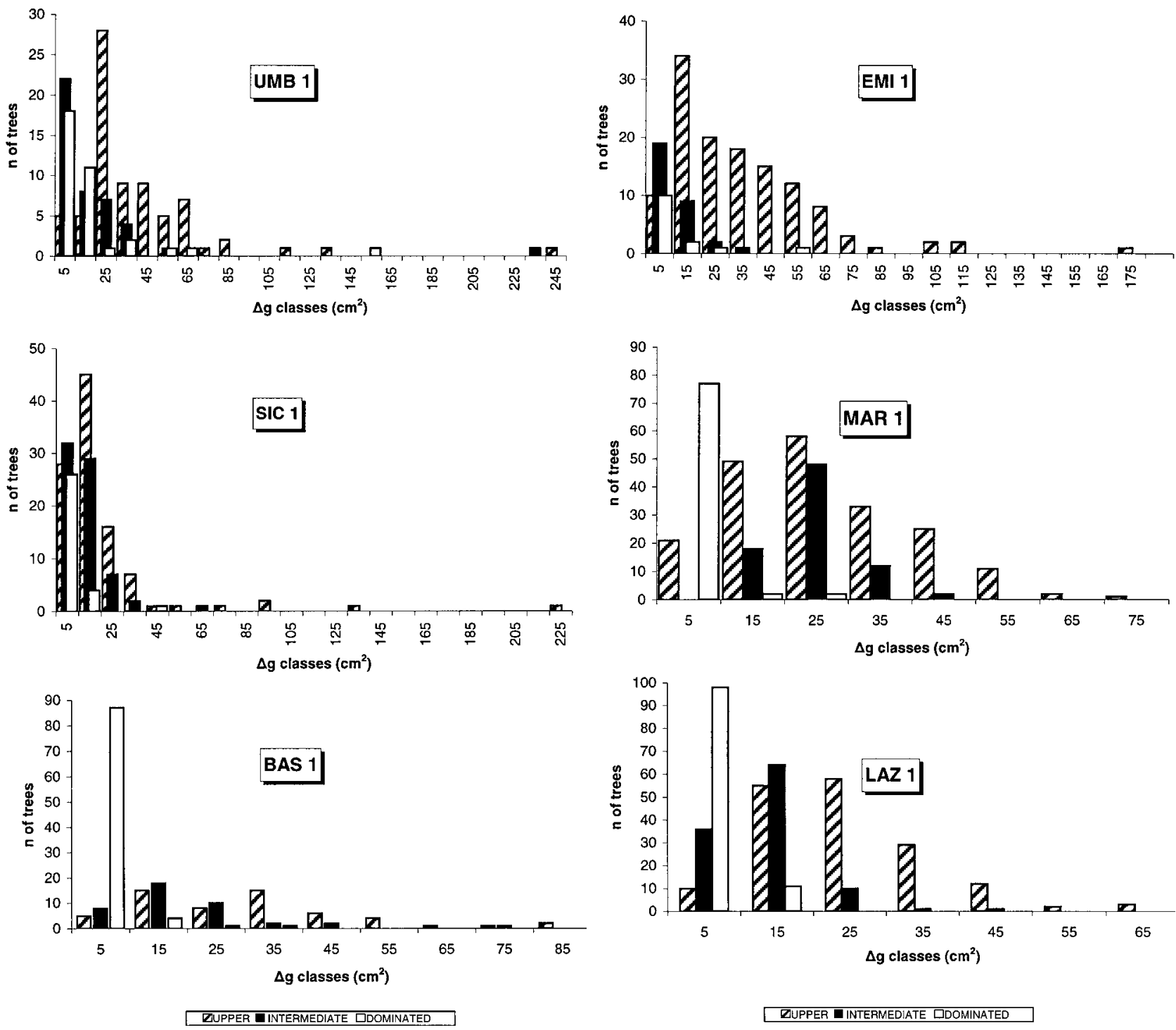

Fig. 4. Distribution of trees per b.a.i. classes $(\Delta \mathrm{g})$ and per layer at Turkey oak forests. Tree frequencies referred to plot area $=2500$ $\mathrm{m}^{2}$.

area increment assessed either including or excluding these counteracting factors. The influence of ingrowth and mortality on the calculation of mean dbh, mean height and relative increments was also highlighted.

Under the assumption that the aim of growth analysis is to discover possible changes in progress (the main goal of intensive forest ecosystem monitoring), a further working hypothesis was explored. After an examination of both inner growth composition and structure, it was found that dominant trees probably produce a more consistent response to general changes in environmental conditions than do intermediate and dominated trees, which are subject to internal competition. For this purpose, average allocation rates and structure of growth in the upper storey may contribute to the analysis, their variations over successive inventories being a wellfounded response to factors affecting tree growth. The procedure tested was especially aimed at reducing the high variability in all measurement parameters within the Italian network and at managing this basic disturbing condition.

We think that any method aimed at improving growth indicators' consistency should be explored. The need for this becomes urgent when massive growth response, i.e. plot growth as a whole, is affected, as in the situation tested, by an evident background noise. We believe that the proposed procedure works well, but involves the assessment of tree social class, not mandatory parameter according to the European survey protocol. 


\section{REFERENCES}

Allavena, S., R. Isopi, B. Petriccione \& E. Pompei (Eds). 1999. Programma Nazionale Integrato per il Controllo degli Ecosistemi Forestali. Ministero per le Politiche Agricole, Roma: 167pp.

Amorini, E. \& G. Fabbio. 1997. Internal report $n^{\circ} 1$ to $N F C$, Rome: $452 \mathrm{pp}$.

Amorini, E. \& G. Fabbio. 2000. Internal report $n^{\circ} 2$ to NFC, Rome: $328 \mathrm{pp}$

Amorini, E., G. Fabbio \& A. Cutini.1999. Studio degli accrescimenti arborei. In: Programma Nazionale Integrato per il Controllo degli Ecosistemi Forestali. Ministero per le Politiche Agricole, Roma: 131-136.

Assmann, E. 1970. The principles of forest yield study. Pergamon Press, Oxford: 506 pp.

Castellani, C. 1982. Tavole stereometriche ed alsometriche costruite per $i$ boschi italiani. Annali Istituto Sperimentale per l'Assestamento Forestale e per l'Alpicoltura, Trento: 277pp.

Cutini, A. 2000. Properties and productivity of crowns and canopy. Contribution to an integrated analysis of forest ecosystem's status. Annali Istituto Sperimentale Selvicoltura - Special Issue CONECOFOR 30 (1999), Arezzo: 91-97.

Cutini, A. 2002. Litterfall and Leaf Area Index in the CONECOFOR Permanent Monitoring Plots. In: Mosello, R., B. Petriccione \& A. Marchetto (Eds), Long-term ecological research in Italian forest ecosystems. J. Limnol., 61 (Suppl. 1): 62-68.

Dobbertin, M., K. Andreassen, M. Neumann \& Z. Somogyi. 2000. Forest growth. Report of the Expert Panel on Forest Growth. Zurigo: $17 \mathrm{pp}$.

Edwards, D. 1998. Issues and themes for natural resources trend and change detection. Ecological Applications, 8(2): 323-325.

Fabbio, G. 1997. Assessment of increment in coppice forests. Report to the Expert Panel on Forest Growth, Zurigo: 5 pp.

Fabbio, G. \& E. Amorini.1999. Studio dell'accrescimento arboreo in ecosistemi forestali. Atti VIII Congresso Nazionale Società Italiana di Ecologia, Lecce: 1 pp.

Fabbio, G. \& E. Amorini. 2000. Tree growth survey and increment assessment. Contribution to the integrated evaluation of ecosystem's status. Annali Istituto Sperimentale Selvicoltura, Special Issue ConEcoFor 30 (1999), Arezzo: 81-89.

Fabbio, G., M.G. Di Lorenzo, M. Frattegiani \& E. Castellucci. 2000. Internal report $n^{\circ} 3$ to $N F C$, Rome: 3 pp.
Ferretti, M. 2000. An introduction to the Integrated and Combined (I\&C) evaluation system designed for the intensive monitoring of forest ecosystems in Italy. Annali Istituto Sperimentale Selvicoltura, Special Issue ConEcoFor 30 (1999), Arezzo: 7-16.

Ferretti, M., F. Bussotti, P. Giordano, C. Mazzali \& R. Nibbi. 2000. CONECOFOR-Integrated and Combined (I\&C) evaluation of risk, status and changes of forest ecosystems. In: Atti (2) SISEF, Bologna: 445-440.

Hamilton, G.J. 1969. The dependence of volume increment of individual trees on dominance, crown dimensions and competition. Forestry, 42: 133-144.

Hara, T. 1986. Growth of individuals in plant populations. Ann. Bot., London, 57: 55-68.

Harper, J.L. 1967. A Darwinian approach to plant ecology. $J$. Ecol., 55: 247-270.

Innes, J.L. (Ed.). 1998. ICP Manual 1998. Part V. Estimation of growth and yield. Federal Research Centre for Forestry and Forest Products (BFH): 1-20.

Innes, J.L. 1998. Measuring environmental change. In: Peterson D.L. \& V.T. Parker (Eds), Ecological Scale. Columbia University Press: 429-457.

Ker, J.W. 1953. Growth of immature douglas-fir by tree classes. Forest Chronicle, 29: 367-373.

Kira, T., H. Ogawa \& N. Sakazaki. 1953. Intraspecific competition among higher plants: I competition-density-yield interrelationship in regularly dispersed populations. Journal of the Institute of Polytechnics, Osaka City University, 1:1-16.

Kozlowski, T.T. \& T.A. Peterson. 1962. Seasonal growth in pine. Botanical Gazette, 124(2): 146-154.

Manetti, M.C. 2002. Tree ring growth by core sampling at the CONECOFOR Permanent Monitoring Plots. The deciduous oak (Quercus cerris L.) type. In: Mosello, R., B. Petriccione \& A. Marchetto (Eds), Long-term ecological research in Italian forest ecosystems. J. Limnol., 61 (Suppl. 1): 55-61.

Oliver, C.D. \& B.C. Larson. 1990. Forest stand dynamics. Mc Graw Hill, New York: 467 pp.

Prodan, M. 1968. Forest biometrics. Pergamon Press, Oxford: $447 \mathrm{pp}$.

Roberts, S.D., J.N. Long \& F. W. Smith. 1993. Canopy stratification and leaf area efficiency: a conceptualisation. For. Ecol. Manage., 60: 143-156.

Stevens, D. 1994. Implementation of a national monitoring program. Journal of Environmental Management, 42: 129. 